Iranian Quarterly Journal of Breast Disease. 2019; 12(3):8.

\section{Original Article \\ Effect of Ear Acupressure on Anxiety and Cortisol Levels in Women Receiving Premastectomy Radiotherapy: A Randomized Clinical Trial}

\author{
Eghdam-Zamiri $\mathbf{R}^{1}$, Dorosti $\mathrm{A}^{2^{*}}$ \\ ${ }^{1}$ Radiology Group, Faculty of Medicine, Tabriz University of Medical Sciences, \\ Tabriz, Iran \\ 2 Anesthesia Group, Faculty of Medicine, Tabriz University of Medical Sciences, \\ Tabriz, Iran
}

\begin{abstract}
Introduction: Radiation therapy before mastectomy increases the severity of stress and cortisol hormone. Because of the preference of patients and physicians for nonpharmacologic stress management methods, we conducted the present study with the aim of evaluating the effect of ear acupressure on anxiety and cortisol hormone levels in women receiving premastectomy radiotherapy.

Methods: This randomized clinical trial was carried out on 66 patients (based on sample size formula) at Imam Reza Hospital in Tabriz during the years 2018-19. The intervention group was given acupressure, twice a day (8 minutes on each ear), for three days before surgery. Serum cortisol level and latent and manifest anxiety (the Spielberger StateTrait Anxiety Inventory) were measured before and after the intervention. Data were analyzed using SPSS 20 software. A P value less than 0.05 were considered significant.
\end{abstract}

Results: There was no significant difference in latent anxiety, manifest anxiety, or cortisol levels between the groups at baseline. Ear acupressure caused a significant decrease in latent anxiety (from $43.22 \pm 6.41$ to $33.09 \pm 4.91$ ), explicit anxiety (from $49.50 \pm 5.52$ to $32.18 \pm 5.01$ ), and plasma cortisol levels (from $156.15 \pm 18.95$ to $115.59 \pm 17.80)(\mathrm{P}<0.005)$, while no significant changes were observed in the control group $(\mathrm{P}>0.05)$.

Conclusion: Ear acupressure can reduce anxiety and stress (cortisol) levels in breast cancer patients undergoing radiotherapy before mastectomy.

Keywords: Ear Acupressure, Stress, Mastectomy, Radiotherapy 
مقدمه: راديوترايى قبل از ماستكتومى موجب افزايش شدت استرس و هورمون كورتيزول

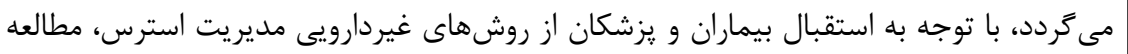

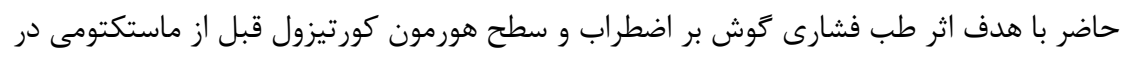
زنان دريافت كننده راديوترايى انجام شد.

روش بررسى: اين مطالعه كارآزمايى بالينى تصادفى شده در طى سالهاى 91

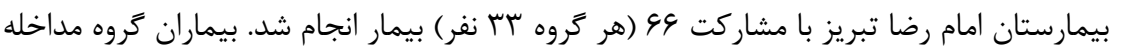

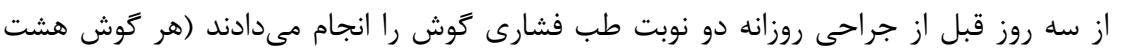

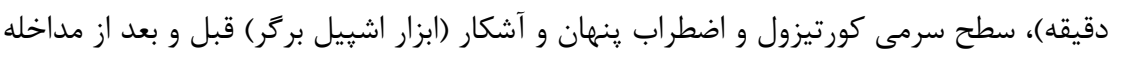

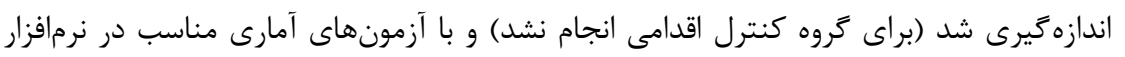

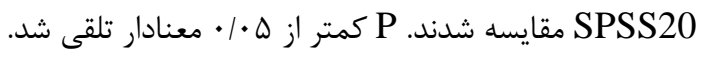

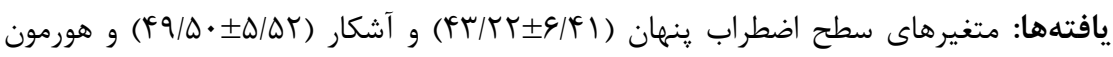

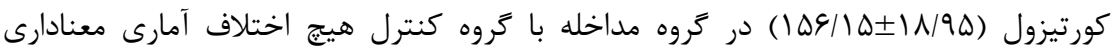

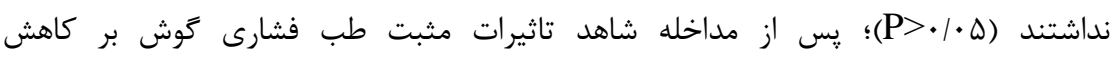

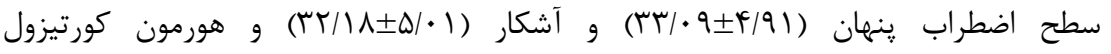

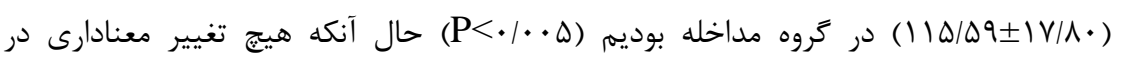

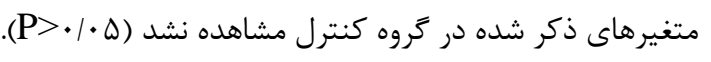

نتيجهَيرى: طب فشارى گوش در بيماران مبتلا به سرطان پستان كه دورههاى راديوترايى را

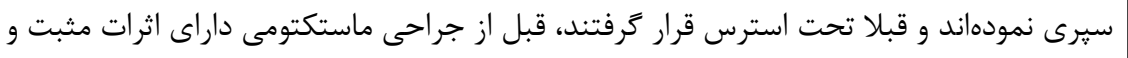

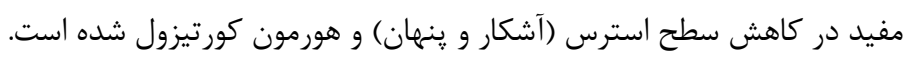
وازههاى كليدى: طب فشارى گوش، استرس، ماستكتومى، راديوترايى 
سرطانى طيف وسيعى از داروها را مصرف مىنمايند،

ممكن است مصرف داروهاى روانيزشكى موجب بروز إنى إنى

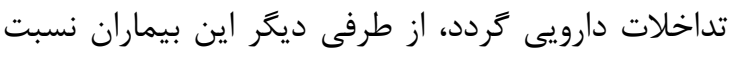

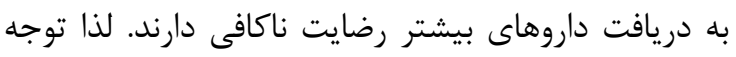
به روشهاى غيردارويى همجون طب مكمل در بيماران سرطانى براى مديريت استرس بيشتر مورد توجه قرار كرفته است (4) (1). يكى از روشهايى كه در طب مكمل است جهت مد مديريت استرس به آن اشاره شده است، طب فشارى توش است

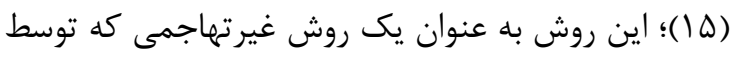

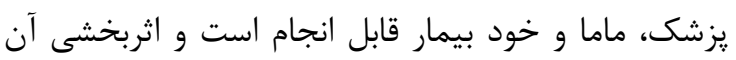
بر مديريت استرس در مطالعات مختلف بررسى و تاييد

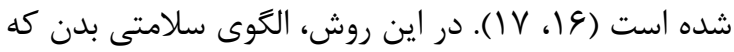
توسط سيكنالهايى كه به وسيله تحريك گوش ايجاد

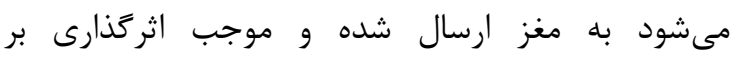
قسمتهاى مختلف بدن مى

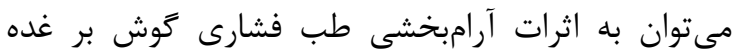

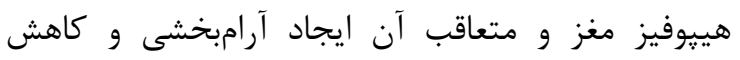

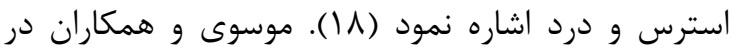

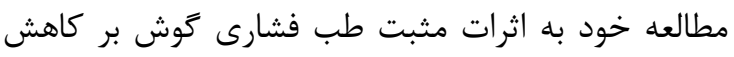

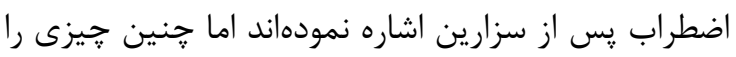

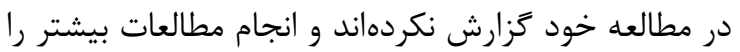

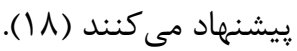

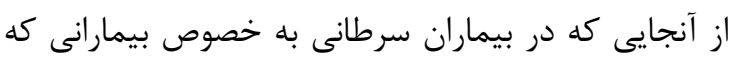

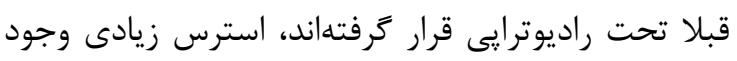
دارد و افزايش استرس بر هورمون كورتيزول موثر است و

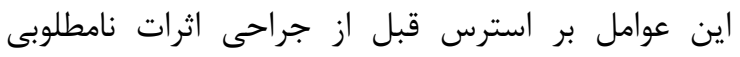

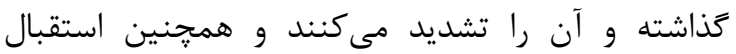
يزشكان و بيماران جهت استفاده از روشهاى غيردارويى

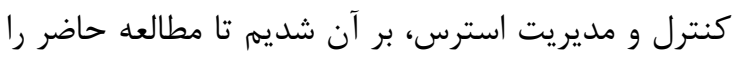

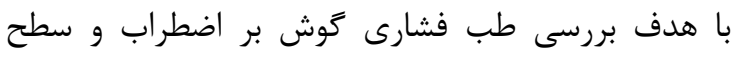

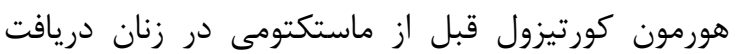
كننده راديوترايى به انجام برسانيم.

\section{مواد و روشها}

اين مطالعه از نوع كارآزمايى بالينى تصادفى شده است كه

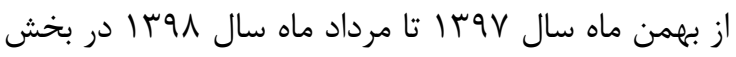
جراحى توراكس بيمارستان امام رضا (وابسته به دانشكاه

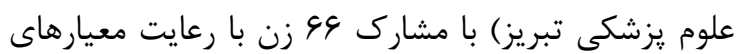

استرس قبل از عمل جراحى به عنوان شايعترين عارضه

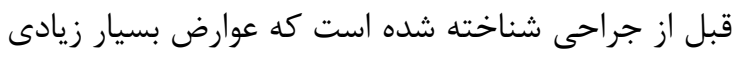

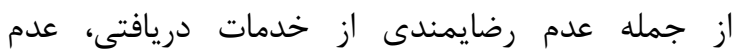

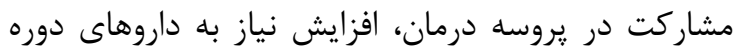

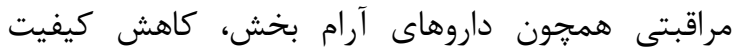

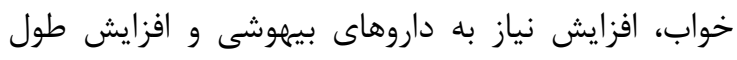

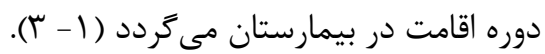

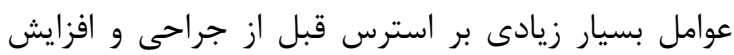

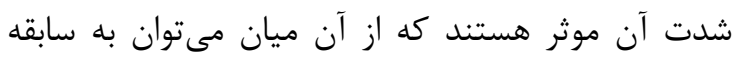

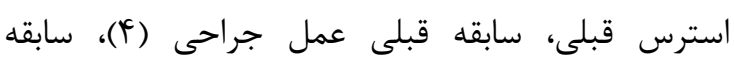
مراقبت از بيماران بدحال جراحى شده، عدم آشنايى با باليا

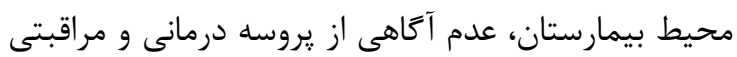

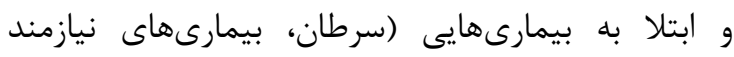

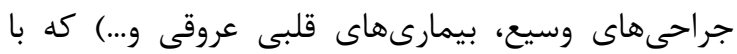
استرس زيادى همراه هستند، اشاره نمود (ل- V). در اين

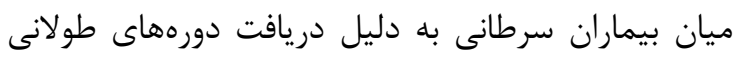

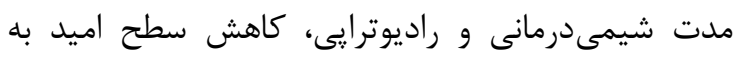
زندگى، افزايش سطح افسردگى، كاهش كيفيت زندگى و

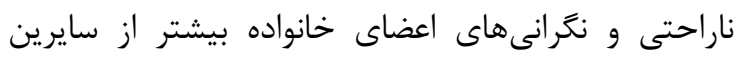
مبتلا به استرس مىشوند (1)، 9) Denaro و همكاران در مطالعه خود جنين بيان مى كنند (رئد

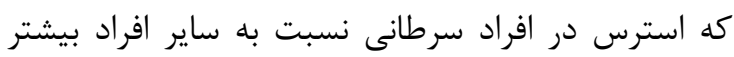

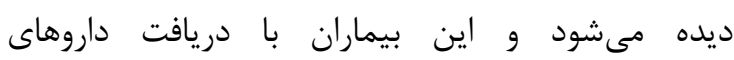

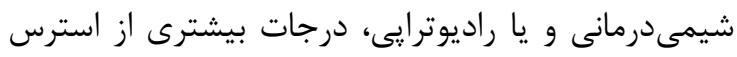

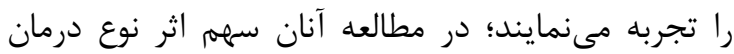

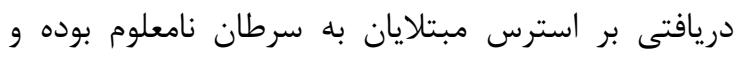

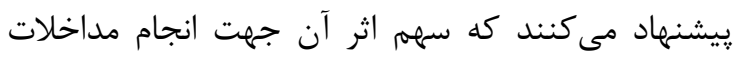

درمانى مشخص كردد (· (1). از طرفى ديخر كورتيزول به عنوان هودرد (ب). هورمون استرس

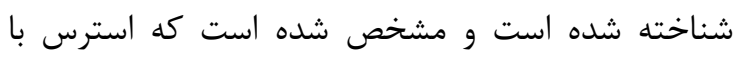
افزايش سطح اين هورمون همراه است؛ افزايش سطح اين

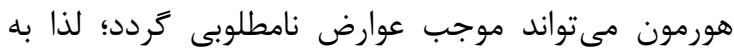

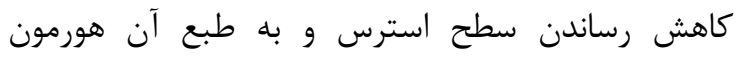
كورتيزول در بيماران سرطانى نسبت به سايرين از اهميت اند انه

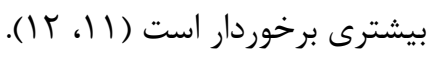

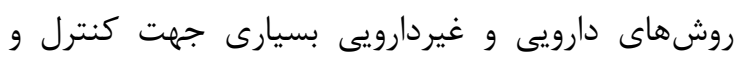
مديريت استرس در بيماران سرطانى توسط محققين ييشنهاد شده است (با)؛ اما با توجه به اينكه بيماران 
بيماران قبل از شروع مداخله و نيم ساعت قبل از ورود

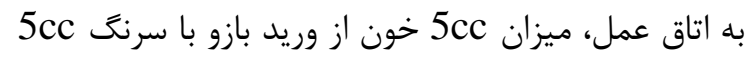

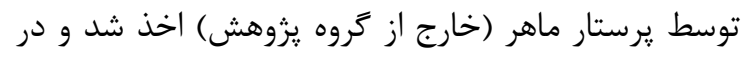

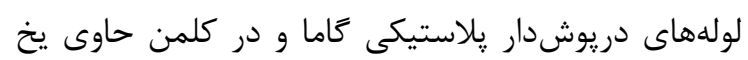

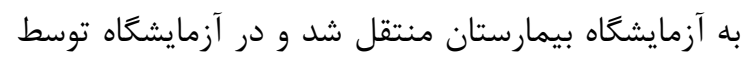

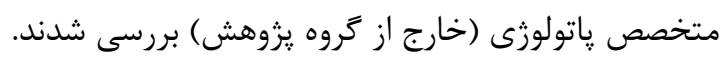

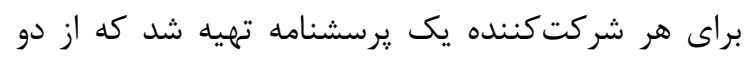

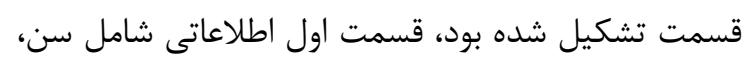
وضعيت تاهل، شغل، سطح تحصيلات، تعداد جلسات

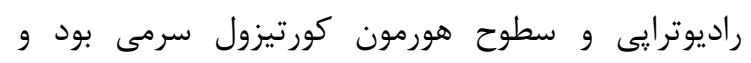

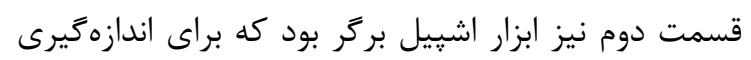
سطح اضطراب ينهان و آشكار مورد استفاده قرار مى ئيرد.

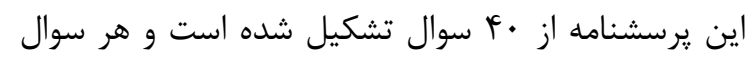

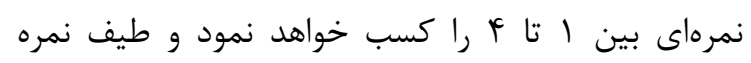

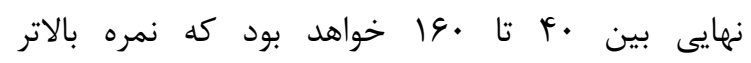
نشاندهنده استرس بالاتر است. قسمت اضطراب ينهاب

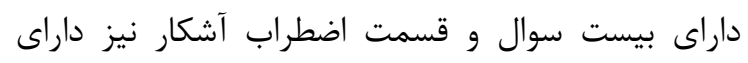

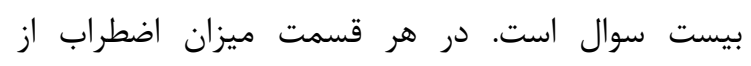

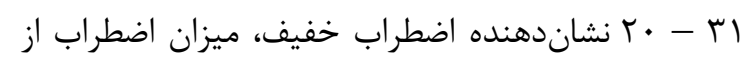

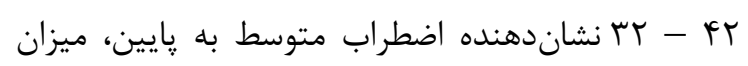

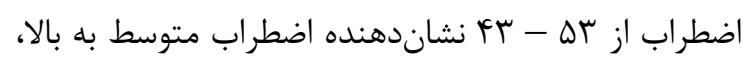

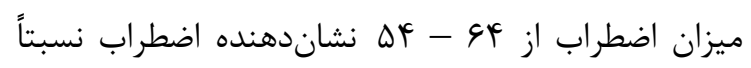

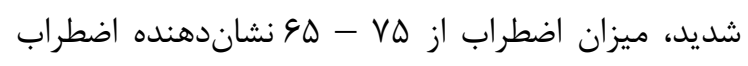

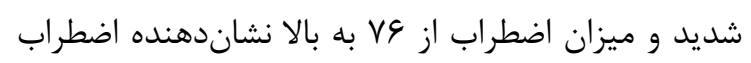

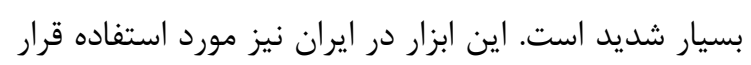

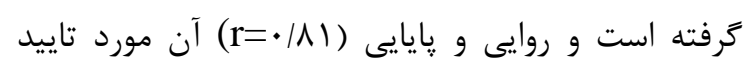

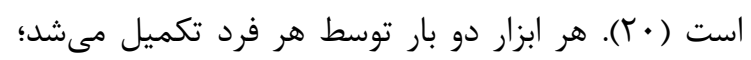

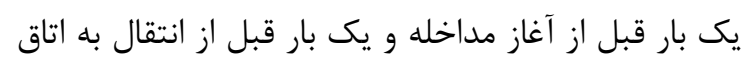

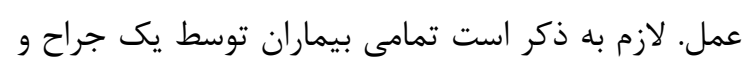

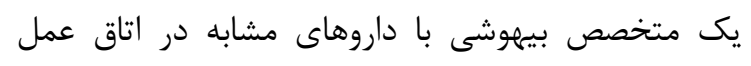
بيهوش و جراحى شدند.

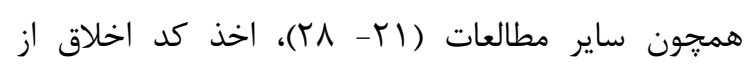

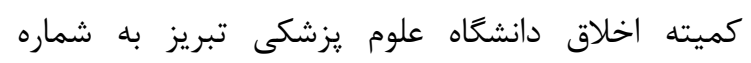
IR.TBZMED.REC.1397.1059 و ثبت در دآ سامانه كارآزمايى بالينى ايران است. اخذ رضايتنامه كتبى از

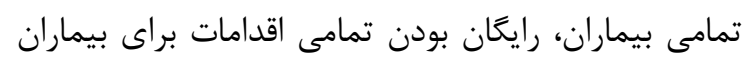

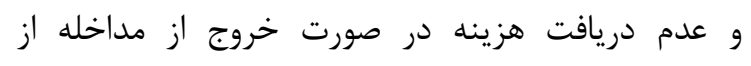
مهممترين ملاحظات اخلاقى رعايت شده در اين مطالعه إنه مدراته
ورود و خروج انجام شد. معيارهاى ورود به مطالعه شامل

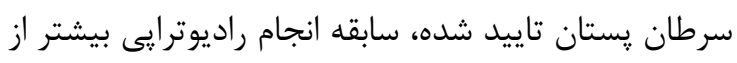
IT جلسه، كانديد عمل جراحى ماستكتومى و سن بيشتر

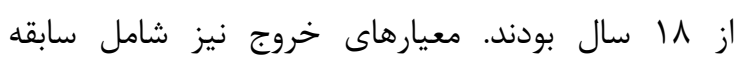
دريافت داروهاى ضد استرس و افسردكى در طى شي شش ماه

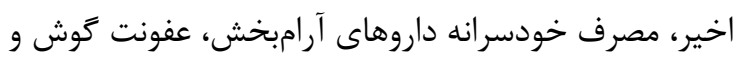
عدم رضايت به شركت در مطالعه بودند.

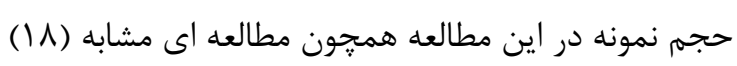

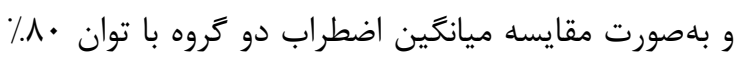

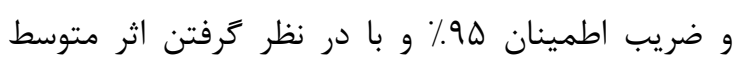

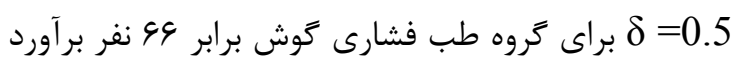

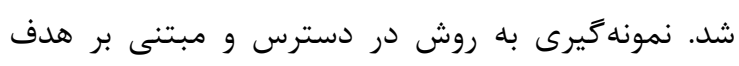

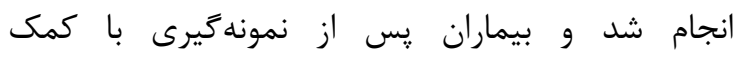

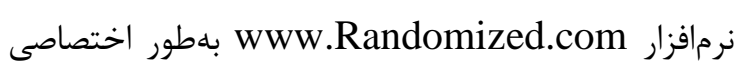
به دو كروه مداخله و شاهد تقسيم شدند. اين مطالعه از

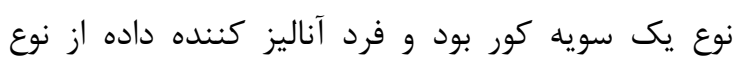

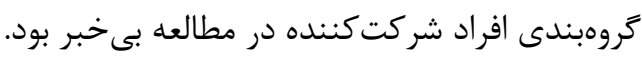

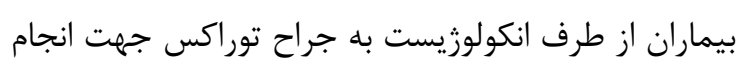
عمل جراحى ماستكتومى معرفى شدند و وِ إن از از تاييد جراح توراكس مبنى بر نياز به ماستكتومى، وارئ مارد مطالعه

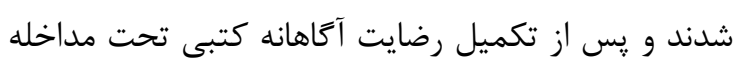

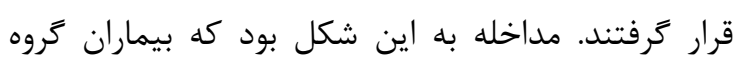

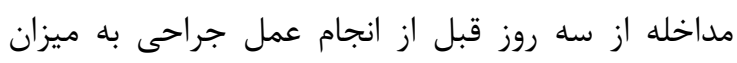

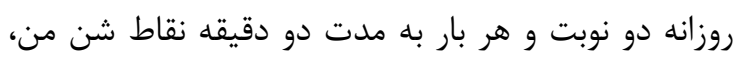

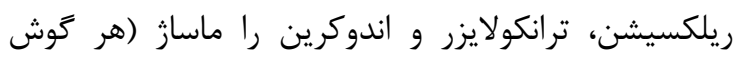
جمعا هشت دقيقه) مى دادند. نحوه انجام مداخله توسط آند

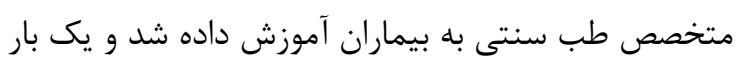

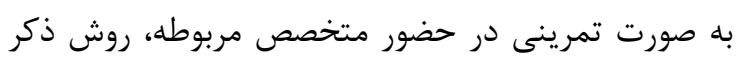

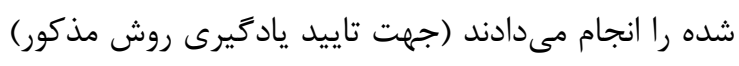

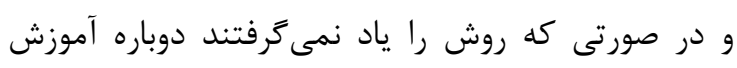

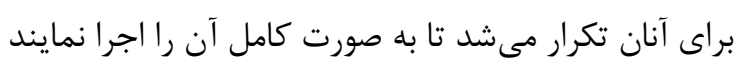

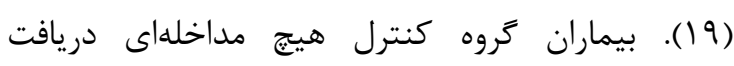
نمى كردند (بيماران كروه كنترل از نحوه دريافت مداخ مدانه

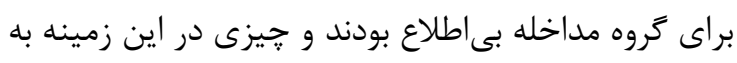

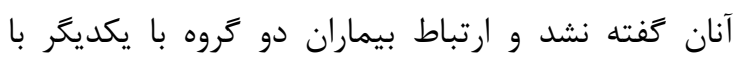
حضور كمك يزوهشكر حاضر در بخش به صفر رند رسيد).

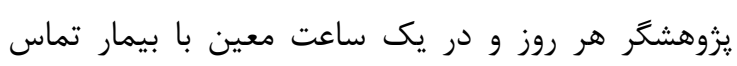

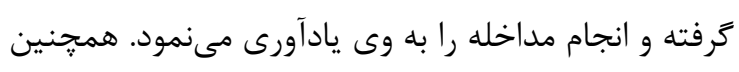
جهت بررسى سطح هورمون كورتيزول سرمى از تمامى 


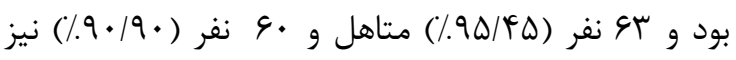

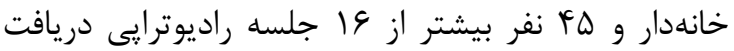

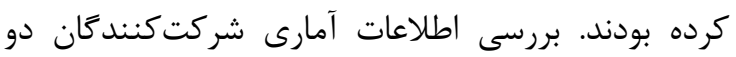
كروه در جدول شماره آ آمده است.

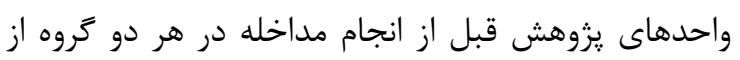

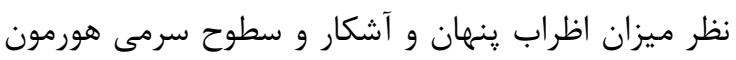

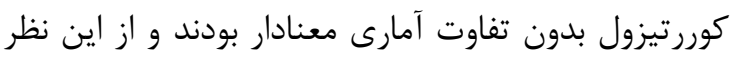

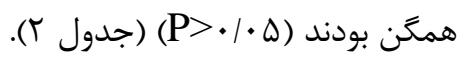
واحدهاى يزوهش يس از انجام مداخله در هر دو كروه از

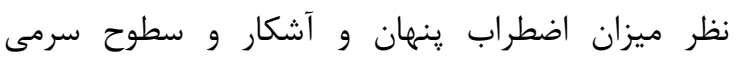

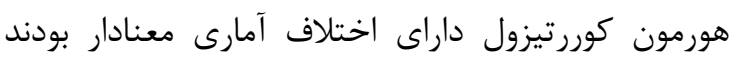
كه نتايج آن در جدول بـ آمده است. مقايسه درون گروهى اطلاعات قبل و يس از از انجام مداخله

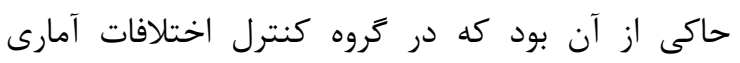

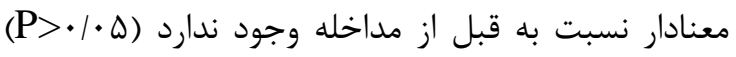
حال آنكه در كروه مداخله شاهد اختلافات آمارى معنادار

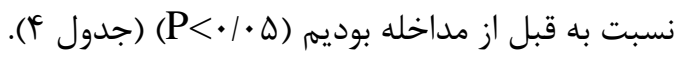

دادهها توسط يزوهشكر جمعآورى شده و در محيط

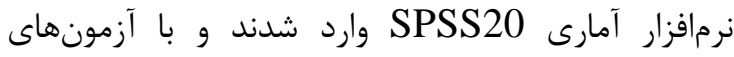

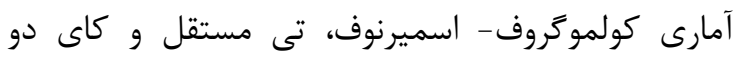

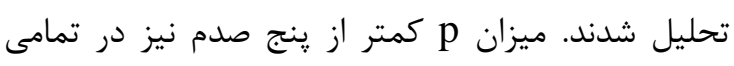

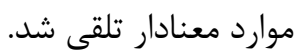

\section{يافتهها}

بررسى كل بيماران (19 نفر) مراجعه كننده به بخش

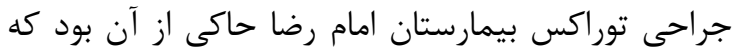

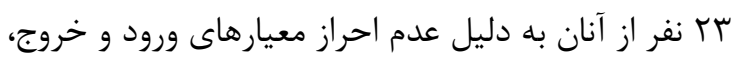

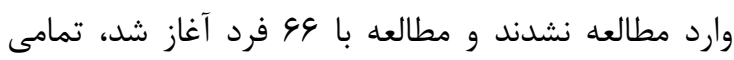

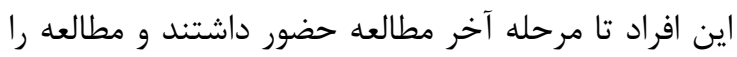

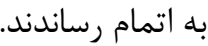
بررسى متغيرها با آزمون كولموكروف- اسميرنوف حاكى از

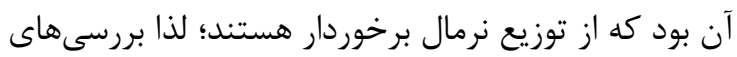

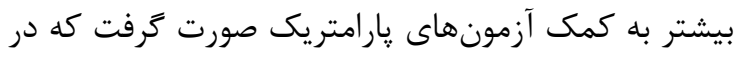

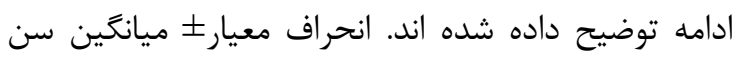

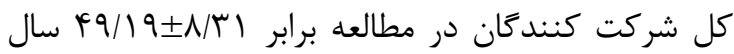

جدول ا: مقايسه مشخصات دموكر افيك شركت كنندكان در مطالعه

\begin{tabular}{|c|c|c|c|}
\hline \multirow{2}{*}{ P Value } & \multicolumn{2}{|c|}{ كروههاى مداخله (n=94) } & \multirow{2}{*}{ متغير مورد بررسى } \\
\hline & كروه مداخله (n=rr) & كروه كنترل ( & \\
\hline $\begin{array}{c}\mathrm{t}=-\cdot / \mathrm{V} \wedge \\
\mathrm{df}=\Delta \cdot \\
\mathrm{P}=\cdot / \mathrm{r}||\end{array}$ & $|\vee q / 19 \pm \wedge / r|$ & $|q q / / q \pm \wedge / r|$ & سن بر حسب سال (Mean \pm (MD) \\
\hline $\mathrm{X} 2=\cdot 1 \cdot \cdots * * *$ & & & وضعيت تاهل \\
\hline $\mathrm{Df}=1$ & r1-\%.9r/9r & $r r-\%$ १९/१९ & 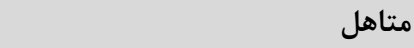 \\
\hline $\mathrm{P}=\cdot / \pi r$ & $r-\% \cdot 91 \cdot 9$ & $1-\% \cdot r / \cdot r$ & 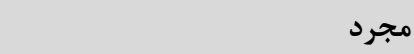 \\
\hline$X 2=\cdot 1 \cdot \cdots * *$ & & & تحصيلات \\
\hline $\mathrm{Df}=1$ & $1 r-\% / r q / r q$ & $\mid T-\% G / T G$ & دانشعاهى \\
\hline $\mathrm{P}=\cdot / r \Delta \mu$ & $|V-\% / \Delta| / \Delta \mid$ & $\mid \Lambda-\% . \Delta F / \Delta F$ & غير دانشعاهى \\
\hline $\mathrm{X} 2=\cdot 1 \cdots * * *$ & & & 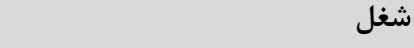 \\
\hline $\mathrm{Df}=1$ & ૨৭-\%.AV/AV & r1-\%.9r/9r & بيكار \\
\hline$P=\cdot \mid 0 \cdot 1$ & $F-\% \mid I / I r$ & $r-\% \cdot 9 / \cdot 9$ & 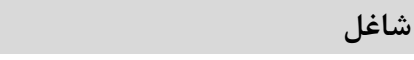 \\
\hline $\mathrm{X} 2=\cdot 1 \cdot \cdots * *$ & & & تعداد جلسات راديوترايى \\
\hline $\mathrm{Df}=1$ & $T Y-\% V T / V T$ & $r 1-\% .9 \Gamma / 9 \mu$ & بيشتر از 19 جلسه \\
\hline $\mathrm{P}=\cdot|\Delta T|$ & $9-\% / r V / r \Lambda$ & $\mid r-\% G / T V$ & كمتر از 19 جلسه \\
\hline
\end{tabular}


جدول r: مقايسه سطوح اضطراب ينههان و آشكار و هورمون كورتيزول شركت كنندَان دو َّروه قبل از مداخله

\begin{tabular}{|c|c|c|c|}
\hline \multirow{2}{*}{ P Value } & \multicolumn{2}{|c|}{ كروههاى مداخله (n=94) } & \multirow{2}{*}{ متغير مورد بررسى } \\
\hline & كروه مداخله (r)=rr) & كروه كنترل (n=rr) & \\
\hline$\cdot / \pi \mid \Delta$ & $|r r / r T \pm g / F|$ & $f \Delta / \cdot 1 \pm \Delta / q$ & اضطراب ينهان (Mean +SD) \\
\hline$\cdot / 4 \cdot 9$ & $r q / \Delta \cdot \pm \Delta / \Delta r$ & $\langle/ / \Delta \Delta \pm \Delta / \cdot r$ & اضطراب آشكار (Mean (Mean) \\
\hline$\cdot / Q \cdot r$ & $|\Delta \varepsilon /| \Delta \pm 1 \wedge / 9 \Delta$ & $|\varepsilon I /| r \pm T \cdot / r \Delta$ & ug/l (Mean ISD) سطح هورمون كورتيزول \\
\hline
\end{tabular}

جدول ب: مقايسه سطوح اضطراب ينهان و آشكار و هورمون كورتيزول شركت كنندكان دو گروه يس از مداخله

\begin{tabular}{|c|c|c|c|}
\hline \multirow{2}{*}{ P Value } & \multicolumn{2}{|c|}{ كروههاى مداخله (n=94) } & \multirow{2}{*}{ 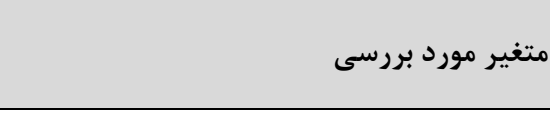 } \\
\hline & كروه مداخله (سr=r) & كروه كنترل (n=r) & \\
\hline$\cdot / \cdot r$ & $r r / \cdot q \pm r / q 1$ & $\tau T / T \Delta \pm \Delta / r$ & اضطراب ینهان (Mean +SD) \\
\hline $.1 \cdot 9$ & $r T / / \Lambda \pm \Delta / \cdot 1$ & $r \cdot / / \Delta \pm \Delta / / r$ & اضطراب آشكار (Mean 土SD) \\
\hline$\cdot 1 \cdot \cdot \Delta$ & $\| \Delta / \Delta q \pm I V / \Lambda$. & $19 \cdot / r 9 \pm r \cdot / 4 \cdot$ & ug/l (Mean +SD) سطح هورمون كورتيزول \\
\hline
\end{tabular}

جدول F: مقايسه درون كروهى اضطراب آشكار و ينهان و كورتيزول قبل و بعد از مداخله بين تروههاى شركت كننده در مطالعه

\begin{tabular}{|c|c|c|c|c|}
\hline هور مون كورتيزول & اضطراب آشكار & اضطراب ينهان & \multicolumn{2}{|c|}{ كروهها ( } \\
\hline $191 / 1 r \pm r \cdot / r \Delta$ & $(r) / \Delta \Delta \pm \Delta / \cdot r$ & $F \Delta / \cdot \mid \pm \Delta / q$. & قبل از مداخله & كنترل \\
\hline $\mid \varepsilon \cdot / r \xi \pm r \cdot / 4$. & $r \cdot / / \Delta \pm \Delta / l r$ & $F r / r \Delta \pm \Delta / r$. & بعد از مداخله & $(n=r r)$ \\
\hline.$|Q| T$ & .1119 & DITI & P Value & $($ Mean \pm SD $)$ \\
\hline$|\Delta я /| \Delta \pm 1 \wedge / 9 \Delta$ & $F q / \Delta \cdot \pm \Delta / \Delta r$ & RT/KTEQ/FI & قبل از مداخله & مداخله \\
\hline$\| \Delta / \Delta ৭ \pm 1 V / \Lambda$. & $r T / / \Lambda \pm \Delta / \cdot 1$ & $r r / \cdot q \pm r / q 1$ & بعد از مداخله & $(n=r r)$ \\
\hline$\cdot / \cdot r$ & r. & $.1 \cdot 9$ & P Value & $($ Mean \pm SD $)$ \\
\hline
\end{tabular}

همكاران (آس) و Feng و همكاران (r (r) همسو بوده و در يك راستا است. در اين راستا Shin و همكاران (سب) كه

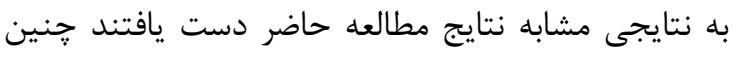

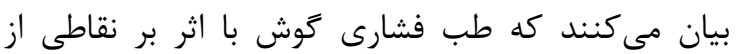
كوش كه موجب بروز ياسخهاى آرامبخش در مغز مىشوند

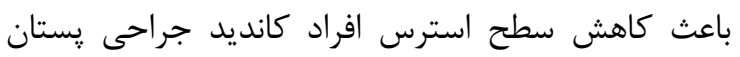
مىشود. محققين ذكر شده در قسمتى ديخر از مطالعه

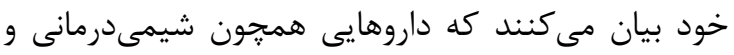
راديوترايى موجب افزايش سطح استرس بيماران قبل از

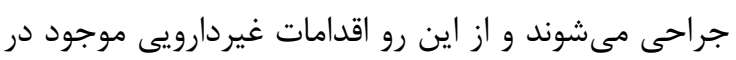
طب مكمل براى اين افراد مفيد خواهد بود. در قسمتى ديكر از مطالعه شاهد نتايج مثبت طب فشارى

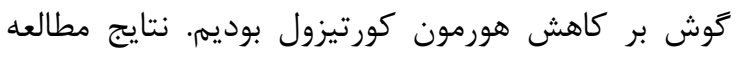

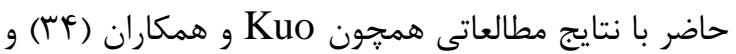
Lukas

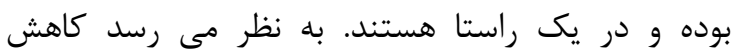

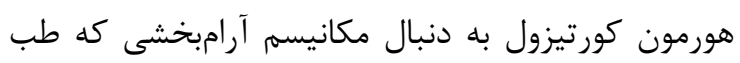

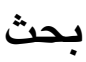

هدف از انجام اين مطالعه بررسى طب فشارى كوش بر

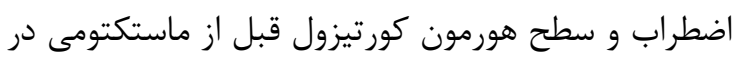

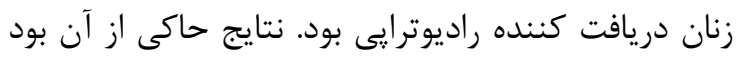

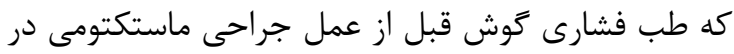
زنان دريافت كننده راديوترايى موجب كاهش آنش استرل

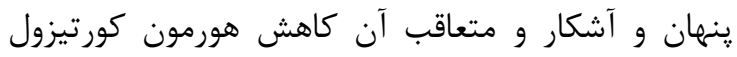
(هورمون نشان دهنده استرس) شده است. بر اساس نتايج

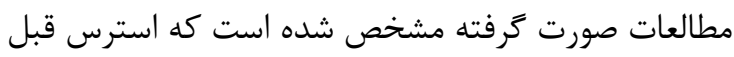

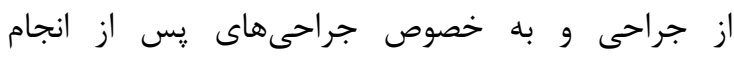

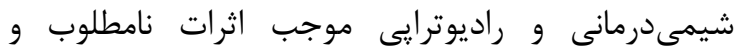
عوارض ناخواسته مى كردد (9) ).

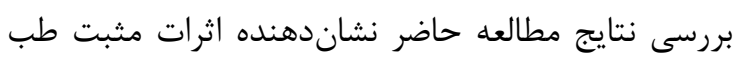
فشارى كوش بر كاهش استرس (ينهان و آشكار) قبل از جراحى ماستكتومى شده است. در اين رابطه نتايج مطالعه

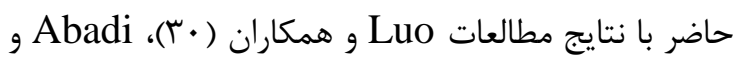




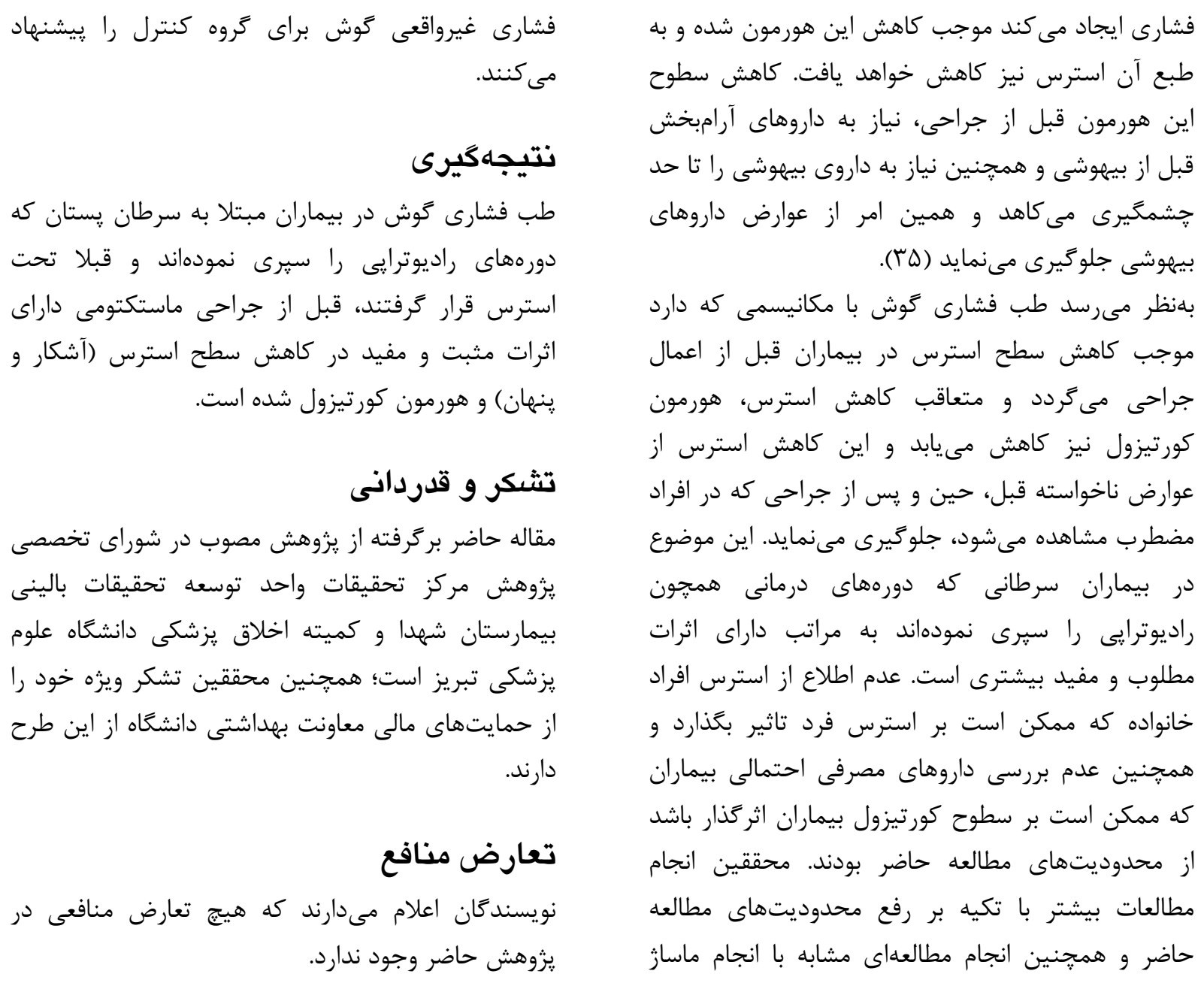

\begin{abstract}
فشارى ايجاد مى كند موجب كاهش اين هورمون شده و به طبع آن استرس نيز كاهش خواهد يافت. كاهش سطوح اين هورمون قبل از جراحى، نياز به داروهاى آرامبخش ناري

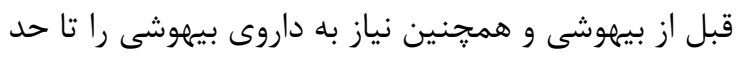

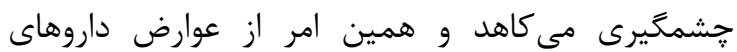
بيهوشى جلو گيرى مىنمايد (ه山). بلنظر مىرسد طب فشارى كوش با مكانيسمى كه دارد موجب كاهش سطح استرس در بيماران قبل از اعمال جراحى مى گردد و متعاقب كاهش استرس، هورمون

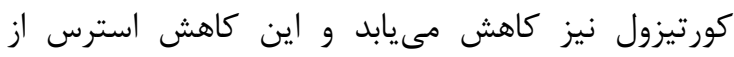

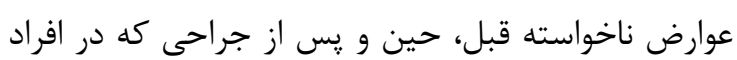
مضطرب مشاهده مىشود، جلوگيرى مىنمايد. اين موضوع

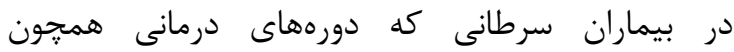

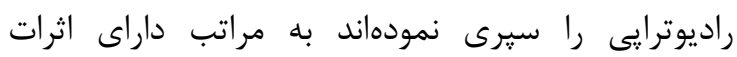
مطلوب و مفيد بيشترى است. عدم اطلاع از استرس افراد إداد

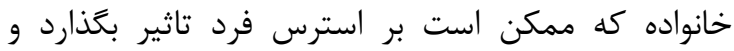

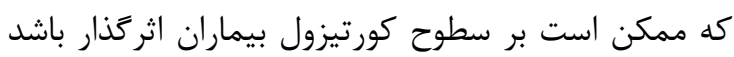

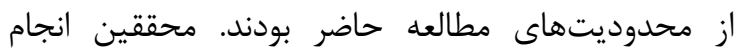
مطالعات بيشتر با تكيه بر رفع محدوديتهاى مطالعه ماندان

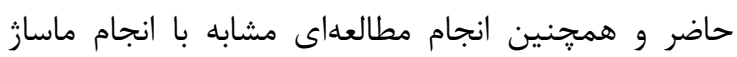
همجنين عدم بررسى داروهاى مصرفى احتمالى بيماران

\section{References}

1. Steinthorsdottir KJ, Kehlet H, Aasvang EK. Surgical stress response and the potential role of preoperative glucocorticoids on post-anesthesia care unit recovery. Minerva anestesiologica. 2017;83(12):1324-31. doi: 10.23736/S03759393.17.11878-X

2. Perdrizet G. Preoperative Stress Conditioning in Humans: Is Oxygen the Drug of Choice? Oxygen Transport to Tissue XXXVII. 2016;876(1):223-31.

3. Gürsoy A, Candaş B, Güner Ş, Yılmaz S. Preoperative stress: an operating room nurse intervention assessment. Journal of PeriAnesthesia Nursing. 2016;31(6):495-503. doi:

https://doi.org/10.1016/j.jopan.2015.08.011.

4. Behrenbruch C, Shembrey C, Paquet-Fifield S, Mølck C, Cho H-J, Michael M, et al. Surgical stress response and promotion of metastasis in colorectal cancer: a complex and heterogeneous process. Clinical \& experimental metastasis. 2018;35(4):333-45. doi: https://doi.org/10.1007/s10585-018-9873-2.

5. Cao J, Wang P-K, Tiwari V, Liang L, Lutz BM, Shieh K-R, et al. Short-term pre-and postoperative stress prolongs incision-induced pain hypersensitivity without changing basal pain perception. Molecular pain. 2015;11(1):73. doi: https://doi.org/10.1186/s12990-015-0077-3.

6. Chatterjee S, Chaubal R, Maitra A, Gardi N, Dutt A, Gupta S, et al. Pre-operative progesterone benefits operable breast cancer patients by modulating surgical stress. Breast cancer research and treatment. 2018;170(2):4318. doi: https://doi.org/10.1007/s10549-0184749-3.

7. Nicewarner HC, Kalesan B, Intwala SS, Leung CK, Balady GJ. A Meta Analysis of Preoperative Stress Testing in the Evaluation of 
Patients Undergoing Non-Cardiac Surgery. Circulation. 2017;136(1):A14605-A.

8. Gaillard H, Garcia-Muse T, Aguilera A. Replication stress and cancer. Nature Reviews Cancer. 2015;15(5):276-280 .doi: https://doi.org/10.1038/nrc3916.

9. De la Roca-Chiapas JM, Barbosa-Sabanero G, Martínez-García JA, Martínez-Soto J, RamosFrausto VM, González-Ramírez LP, et al. Impact of stress and levels of corticosterone on the development of breast cancer in rats. Psychology research and behavior management. 2016;9:1-9. doi: 10.2147/PRBM.S94177.

10. Denaro N, Tomasello L, Russi EG. Cancer and stress: what's matter? from epidemiology: the psychologist and oncologist point of view. Journal of cancer therapeutics and research. 2014;3(1):6.

doi: http://dx.doi.org/10.7243/2049-7962-3-6.

11. Kidd T, Carvalho LA, Steptoe A. The relationship between cortisol responses to laboratory stress and cortisol profiles in daily life. Biological psychology. 2014;99:34-40. doi : https://doi.org/10.1016/j.biopsycho.2014.02.010

12. Schrepf A, Thaker PH, Goodheart MJ, Bender D, Slavich GM, Dahmoush L, et al. Diurnal cortisol and survival in epithelial ovarian cancer. Psychoneuroendocrinology. 2015;53:256-67. doi: https://doi.org/10.1016/j.psyneuen.2015.01.010.

13. Stagl JM, Lechner SC, Carver CS, Bouchard LC, Gudenkauf LM, Jutagir DR, et al. A randomized controlled trial of cognitivebehavioral stress management in breast cancer: survival and recurrence at 11-year follow-up. Breast cancer research and treatment. 2015;154(2):319-28. doi: https://doi.org/10.1007/s10549-015-3626-6.

14. Carpenter KM, Stoner SA, Schmitz K, McGregor BA, Doorenbos AZ. An online stress management workbook for breast cancer. Journal of behavioral medicine .2014;37(3):45868 .doi: https://doi.org/10.1007/s10865-0129481-6.

15. Hadizadeh Talasaz $\mathrm{Z}$, Khadivzadeh $\mathrm{T}$, Firoozi M, Azizi H, Irani M. The Usage of Ear Acupressure in Gynecology and Obstetrics: A Systematic Review of Clinical Trials. The Iranian Journal of Obstetrics, Gynecology and Infertility. 2018;21(01):42-54. doi: 10.22038/ijogi.2018.11620.

16. Saffari M, Khashavi Z, Valiani M. The effect of auriculotherapy on the stress and the outcomes of assistant reproductive technologies in infertile women. Iranian journal of nursing and midwifery research. 2018;23(1):8. doi: 10.4103/ijnmr.IJNMR_105_16.

17. Wang Y-J, Hsu C-C, Yeh M-L, Lin J-G. Auricular acupressure to improve menstrual pain and menstrual distress and heart rate variability for primary dysmenorrhea in youth with stress. Evidence-Based Complementary and Alternative Medicine. 2013; 138537:1-8. doi: http://dx.doi.org/10.1155/2013/138537.

18. Mousavi FS, Golmakani N, Taghanaki B, Reza H, Saki A, Akhlaghi F. Effects of auriculotherapy on post cesarean anxiety. The Iranian Journal of Obstetrics, Gynecology and Infertility. 2017;20(6):50-60. doi: doi: 10.22038/ijogi.2017.9325.

19. Valiani M, Mansourian M, Ashtari F. The Effect of Auriculotherapy on Stress, Anxiety, and Depression in MS Patients: A Double Blind Randomized Clinical Control Trial (Parallel Design). ACTA MEDICA MEDITERRANEA. 2018;34:561-7.

20. Mahram B. Validation of Eshpil berger anxiety test in Mashhad: Thesis in Persian]. Tehran: University of Education; 1994.

21. Abdollahi M-H, Foruzan-Nia K, Behjati M, Bagheri B, Khanbabayi-Gol M, Dareshiri S, et al. The effect of preoperative intravenous paracetamol administration on postoperative fever in pediatrics cardiac surgery. Nigerian medical journal: journal of the Nigeria Medical Association. 2014;55(5): 379.

22. Aghamohammadi D, Mehdinavaz Aghdam A, Khanbabayi Gol M. Prevalence of Infections Associated with Port and Predisposing Factors in Women with Common Cancers Under Chemotherapy Referred to Hospitals in Tabriz in 2015. The Iranian Journal of Obstetrics, Gynecology and Infertility. 2019;21(11):7-13.

23. Gol MK, Aghamohamadi D. Analgesic Effects of Ozone on Celiac Plexus Neurolysis, Reduced Need for Opioids, and Quality of Life in Patients with Pancreatic Cancer.2019;Soesial issue(2): 165-9.

24. Gol MK, Dorosti A, Montazer M. Design and psychometrics cultural competence questionnaire for health promotion of Iranian nurses. Journal of education and health promotion. 2019;8-155.

25. Mobaraki-Asl N, Ghavami Z, Gol MK. Development and validation of a cultural competence questionnaire for health promotion of Iranian midwives. Journal of Education and Health Promotion. 2019;8(1):179.

26. Dehdilani M, Gol MK, Hashemzadeh K. Effects of Stretching Exercises on Upper 
Crossed Syndrome in Women after a Coronary Artery Bypass Graft .Crescent Journal of Medical and Biological Sciences.6(3):350-354.

27. Goljabini S, Hemmati Maslak Pak M, Farzin H, Khanbabayi Gol M. The Eeffect of clinicalbased clinical training on nurses'performance in the prevention of ventilator associated pneumonia in special wardd of Urmia educational center in night shift. The J Urmia Nurs Midwifery Fac. 2018;15(11):843-50.

28. Kanbabayi Gol M, Zamanzadeh V, Jabarzadeh F. Cultural Competence Among Senior Nursing Students Of Medical Universitis In North-west Iran. The J Urmia Nurs Midwifery Fac. 2017;15(8):612-9.

29. Peterson B, Ghahramani M, Emerich M, Foy AJ. Frequency of appropriate and low-risk noncardiac preoperative stress testing across medical specialties. The American journal of cardiology. 2018;122(5):744-8. doi : https://doi.org/10.1016/j.amjcard.2018. 05.007.

30. Luo L, Dai Q, Mo Y, Yan Y, Qian M, Zhuang $\mathrm{X}$, et al. The effect of auricular acupressure on preoperative anxiety in patients undergoing gynecological surgery. Int $\mathbf{J}$ Clin Exp Med. 2016;9(2):4065-70.

31. Abadi F, Abadi F, Fereidouni Z, Amirkhani M, Karimi S, Kalyani MN. Effect of Acupressure on Preoperative Cesarean Section Anxiety. Journal of acupuncture and meridian studies.

2018;11(6):361-6. doi: https://doi.org/10.1016/j.jams.2018.07.001.

32. Feng F, Han M, Zhu B, Kang F, Juan L. Effect of the acupressure wristbands combined with tropisetron on quality of recovery during early period after radical mastectomy. The Journal of Clinical Anesthesiology. 2018;34(4):348-51.

33. Shin J, Park H. Effects of auricular acupressure on constipation in patients with breast cancer receiving chemotherapy: a randomized control trial. Western journal of nursing research. 2018;40(1):67-83. doi: https://doi.org/10.1177/0193945916680362.

34. Kuo S-Y, Tsai S-H, Chen S-L, Tzeng Y-L. Auricular acupressure relieves anxiety and fatigue, and reduces cortisol levels in postcaesarean section women: A single-blind, randomised controlled study. International journal of nursing studies. 2016;53:17-26. doi: https://doi.org/10.1016/j.ijnurstu.2015.10.006.

35. Sedighinejad A, Imantalab V, Mirmansouri A, Nabi BN, Tarbiat M, Sadeghi AM, et al. Comparing the effects of isoflurane-sufentanil anesthesia and propofol-sufentanil anesthesia on serum cortisol levels in open heart surgery with cardiopulmonary bypass. Anesthesiology and pain medicine. 2016;6(6):100-9. doi: 10.5812/aapm.42066. 